\title{
Nitrogen fluxes from the landscape are controlled by net anthropogenic nitrogen inputs and by climate
}

\author{
Robert Howarth ${ }^{1 *}$, Dennis Swaney ${ }^{1}$, Gilles Billen ${ }^{2}$, Josette Garnier ${ }^{2}$, Bongghi Hong ${ }^{1}$, Christoph Humborg ${ }^{3}$, \\ Penny Johnes ${ }^{4}$, Carl-Magnus Mörth ${ }^{3}$, and Roxanne Marino ${ }^{1}$
}

The flux of nitrogen $(\mathrm{N})$ to coastal marine ecosystems is strongly correlated with the "net anthropogenic nitrogen inputs" (NANI) to the landscape across 154 watersheds, ranging in size from $16 \mathrm{~km}^{2}$ to $279000 \mathrm{~km}^{2}$, in the US and Europe. When NANI values are greater than $1070 \mathrm{~kg} \mathrm{~N} \mathrm{~km}^{-2} \mathrm{yr}^{-1}$, an average of $25 \%$ of the NANI is exported from those watersheds in rivers. Our analysis suggests a possible threshold at lower NANI levels, with a smaller fraction exported when NANI values are below $1070 \mathrm{~kg} \mathrm{~N} \mathrm{~km}^{-2} \mathrm{yr}^{-1}$. Synthetic fertilizer is the largest component of NANI in many watersheds, but other inputs also contribute substantially to the $\mathrm{N}$ fluxes; in some regions, atmospheric deposition of $\mathrm{N}$ is the major component. The flux of $\mathrm{N}$ to coastal areas is controlled in part by climate, and a higher percentage of NANI is exported in rivers, from watersheds that have higher freshwater discharge.

Front Ecol Environ 2012; 10(1): 37-43, doi:10.1890/100178 (published online 15 Jul 2011)

$\mathrm{E}^{\mathrm{x}}$ xcessive amounts of nitrogen $(\mathrm{N})$ represent the largest pollution problem in coastal marine waters. Human activity has increased $\mathrm{N}$ inputs by 10 - to 15 -fold in many regions, but has had little effect in others (NRC 2000; Howarth et al. 2005, 2011). Nitrogen derives from many sources, and different sources of $\mathrm{N}$ dominate in different areas. Over 20 years ago, Peierls et al. (1991) demonstrated a correlation between human population density and nitrate fluxes in very large rivers and suggested that sewage was the primary cause, with perhaps a contribution from atmospheric deposition. At the coarse scale they applied, other drivers, including fertilizer and

\section{In a nutshell:}

- Nitrogen $(\mathrm{N})$ pollution is one of the primary threats to the ecological integrity of estuaries and other coastal marine ecosystems

- Although synthetic fertilizer is the main source of $\mathrm{N}$ pollution in many areas, other sources - such as atmospheric deposition and the movement of $\mathrm{N}$ in food and animal feeds - contribute, and are sometimes dominant

- $\mathrm{N}$ fluxes in rivers to coastal ecosystems increase as the "net anthropogenic nitrogen inputs" (NANI) to the landscape increase

- NANI provides a powerful approach for estimating these $\mathrm{N}$ fluxes and for determining the major sources of $\mathrm{N}$ pollution in the landscape

${ }^{1}$ Department of Ecology and Evolutionary Biology, Cornell University, Ithaca, NY*(howarth@cornell.edu); ${ }^{2}$ UMPC Université Paris 6 and CNRS, UMR Sisyphe, Paris, France; ${ }^{3}$ Baltic NEST Institute, Stockholm Resilience Centre, Stockholm, Sweden; ${ }^{4}$ Aquatic Environments Research Centre, School of Human and Environmental Sciences, University of Reading, Whiteknights, Reading, UK other agricultural inputs, could not be discerned. Today, the relative contribution of sources to coastal $\mathrm{N}$ pollution remains uncertain in many cases, in part because no direct approaches for making such evaluations exist. In such instances, models provide the only robust assessment tool (EPA-SAB 2008).

In one paper from a 1994 workshop, Howarth et al. (1996) examined the flux of $\mathrm{N}$ from large watershed regions to the North Atlantic Ocean in the context of the $\mathrm{N}$ inputs to the landscape from human activity. Inputs considered were use of synthetic $\mathrm{N}$ fertilizer, $\mathrm{N}$ fixation associated with agricultural crops, atmospheric deposition of oxidized $\mathrm{N}\left(\mathrm{NO}_{y}\right)$, and the net movement of $\mathrm{N}$ into or out of the region in human food and animal feeds. We termed the sum of these inputs the "net anthropogenic nitrogen inputs", or NANI. At the coarse scale of large regions surrounding the North Atlantic Ocean, the average multi-year flux of $\mathrm{N}$ transported in rivers to the North Atlantic was well correlated with NANI. Alexander et al. (2002) compared many models for estimating $\mathrm{N}$ fluxes in large river basins and concluded that a simple model that predicts $\mathrm{N}$ flux as a linear function of NANI was one of the most accurate, with low bias and error as compared with those of more complicated models. This simple model has since been used to estimate the total riverine $\mathrm{N}$ flux from the global landscape to the world's oceans (Galloway et al. 2004; Boyer et al. 2006).

NANI does not include sewage or animal wastes because these are simply flows of $\mathrm{N}$ that originate from other sources already included in NANI. Similarly, the only atmospheric input considered is $\mathrm{NO}_{y}$ deposition, which in the temperate zone originates largely from fossilfuel combustion and is therefore a new input of $\mathrm{N}$ to the 

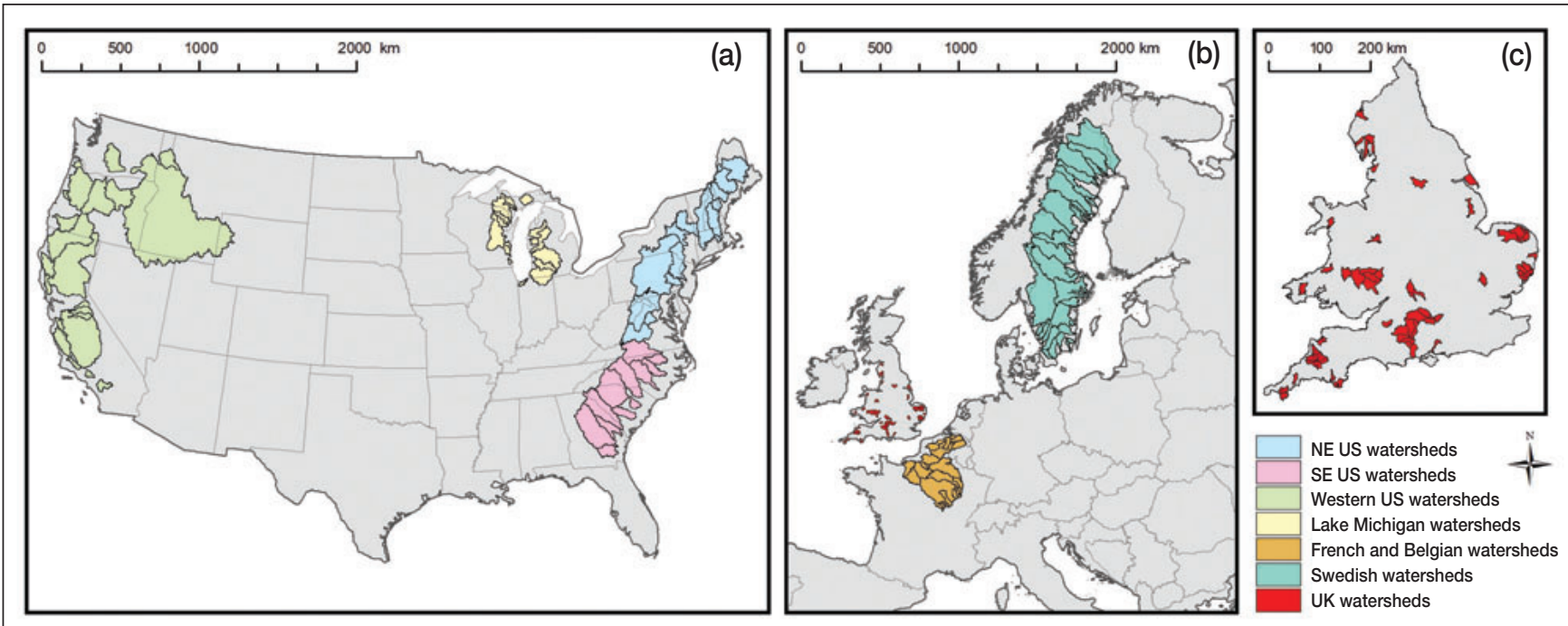

Figure 1. Maps showing the distribution of the watersheds included in our analysis (a) in the US and (b) in Europe. The watersheds in the UK are shown both in the European map and (c) in the more detailed map of the UK.

landscape. Deposition of ammonia is excluded, given that most of the ammonia in the atmosphere is deposited near the site of emission to the atmosphere (ie within the same region) and originates from agricultural sources already included in NANI (Howarth et al. 1996, 2006).

The NANI approach, or the closely related approach of considering total $\mathrm{N}$ inputs (TNI, which is equivalent to NANI plus natural $\mathrm{N}$ fixation), has been applied in many regions, including the northeastern US (Alexander et al. 2002; Boyer et al. 2002; Howarth et al. 2006), the southeastern US (Schaefer and Alber 2007), many of the watersheds on the west coast of the US (Schaefer et al. 2009), and watersheds in Michigan (Han and Allan 2008). In all of these cases, riverine $\mathrm{N}$ fluxes were well correlated with NANI (or TNI), but the percentage of the $\mathrm{N}$ inputs exported in rivers varied among the regions. Several of these previous studies suggested that the fraction of NANI exported in riverine flows is related to climatic variables, including precipitation, temperature, and freshwater discharge. However, the conclusions of these studies often contradicted one another. We hypothesized that the influence of climate on the relationship of NANI and riverine $\mathrm{N}$ flux might become clearer if a larger set of watersheds from a diversity of regions were considered. Here, we report on such a study, one that includes 154 US and European watersheds.

\section{Data sources}

Our analysis included watersheds in the US, France, Belgium, the UK, and Sweden (Figure 1). The watersheds varied considerably in size, from $16 \mathrm{~km}^{2}$ to $279000 \mathrm{~km}^{2}$. The US watersheds included 16 in the Northeast (Boyer et al. 2002; Howarth et al. 2006), 12 in the Southeast (Schaefer and Alber 2007), 17 in the West (Schaefer et al. 2009), and 18 in the Upper Midwest (Han and Allan 2008). For the US watersheds, we used published data
(Howarth et al. 2006; Schaefer and Alber 2007; Schaefer et al. 2009; Han and Allan 2008) for estimates of area, average discharge, average temperature, and riverine total N flux (see WebTable 1), and for 3 out of 4 of the input terms for NANI: synthetic fertilizer, $\mathrm{N}$ fixation in agroecosystems, and the net input of $\mathrm{N}$ in human food and animal feeds. These data generally come from the county scale. To estimate the fourth input term - $\mathrm{NO}_{\text {, }}$ deposition - we used output from the US Environmental Protection Agency's Community Multi-scale Air Quality (CMAQ) system rather than the $\mathrm{NO}_{v}$ deposition estimates reported in the original papers. CMAQ is an emissions-based model that predicts total oxidized deposition, including gases across the US, at a grid of $36 \mathrm{~km} \times 36 \mathrm{~km}$ (www.cmaq-model.org/).

The European watersheds included 25 in France and Belgium, 30 in the UK, and 36 in Sweden (WebTable 1). The French and Belgian basins included the Seine, Somme, and Scheldt watersheds and 22 nested subbasins; these basins and the approach used for estimating the NANI terms are described in Billen et al. (2009). The NANI budgets for the UK watersheds were constructed through government (Department for Environment, Food and Rural Affairs) statistics on food and feed import/export for the UK, and UN Food and Agriculture Organization (FAO) and UK statistics on precipitation, discharge, climatic variables, riverine $\mathrm{N}$ flux, and the $\mathrm{N}$ content of food and feed consumed in the UK, following the approach outlined by Boyer et al. (2002). Background data for the UK watersheds were derived from a range of sources, including research reports for the UK Environment Agency, and published studies (see WebReferences). For all Swedish watersheds, we used agricultural statistics obtained from the Statistiska-Centralbyrån for 1995 (www.scb.se). We constructed food and feed budgets following Boyer et al. (2002), using the statistical agricultural data together with FAO statistics. Fertilizer 
use data were obtained from Eurostat (http://epp.eurostat.ec.europa.eu/). Riverine $\mathrm{N}$ flux, climatic, and atmospheric deposition data were collected from the Baltic Environmental Database (http://nest.su.se/models/bed. htm). For all the European watersheds, we derived deposition estimates from the European Monitoring and Evaluation Programme's model, an emissions-based model similar to CMAQ, using a grid of $50 \mathrm{~km} \times 50$ $\mathrm{km}$. For the other NANI terms, estimates were generally based on the finest scale of administrative government unit for which information was available, roughly equivalent to county-scale data in the US.

For all watersheds included in this paper, the riverine $\mathrm{N}$ fluxes reported are multi-year averages, usually for 6 or 7 years. The NANI estimates come from a single-year period within those 6 or 7 years. Note that NANI generally does not vary greatly over short time intervals (Hong et al. 2011).

\section{Riverine $\mathrm{N}$ flows and NANI}

Riverine $\mathrm{N}$ flux from the 154 watersheds is significantly correlated with NANI on both linear and log-log scales (Figure 2, a and b). The slope of the regression on the linear scale (Figure 2a) indicates that, on average, approximately $25 \%$ of NANI is exported in the rivers included in this study. The slope for the single-line fit in the log-log plot is less, but we also explored a threshold response in the log-log relationship by using a piecewise linear fit. The existence of a threshold might indicate some saturation process at the watershed scale, as was previously observed at smaller scales for inputs of $\mathrm{N}$ from atmospheric deposition to forests (Aber et al. 2003) and for fertilizer inputs to agroecosystems (Howarth et al. 2005; Billen et al. 2007). The piecewise linear fit to the log-log relationship suggests a threshold response at a NANI value of approximately $1070 \mathrm{~kg} \mathrm{~N}$ $\mathrm{km}^{-2} \mathrm{yr}^{-1}$, with the slope of the line above this threshold being virtually the same as for the linear fit in Figure 2a and indicating that $25 \%$ of NANI is exported in rivers. At lower levels of NANI, the percentage of NANI exported appears to be less than $25 \%$.

The fate of NANI that is not exported in rivers - some $75 \%$ on average at higher NANI levels - remains poorly known. For the northeastern US, the best available evidence suggests that some is retained in soils and forest biomass, but more is denitrified (van Breemen et al.
2002). A better understanding of the fate of non-riverexported NANI is critical if we are to predict how sinks and fluxes may change in the future as a result of climate change, land-use change, and saturation of some sinks.

The NANI approach was originally developed for very large regions (such as the entire northeastern US from Maine through Virginia, or the entire Mississippi River basin), and has subsequently been applied to smaller but generally still large - watersheds (Alexander et al. 2002; Howarth et al. 2006; Schaefer and Alber 2007; Han and Allan 2008; Schaefer et al. 2009). For several reasons, one might expect the approach to be more robust at larger spatial scales and to break down below some threshold watershed size. For example, cross-boundary transfer of ammonia in the atmosphere is small relative to other NANI terms at large spatial scales but becomes increasingly important at smaller scales (Howarth et al. 2006). Also, the NANI approach is presumably most robust when watersheds are large relative to the scale of input data. For $\mathrm{NO}_{y}$ deposition in the US, this spatial scale for input data is $1296 \mathrm{~km}^{2}$, and for some other data in 
(a) Riverine $\mathbf{N}$ flux as a function of fertilizer inputs for all watersheds

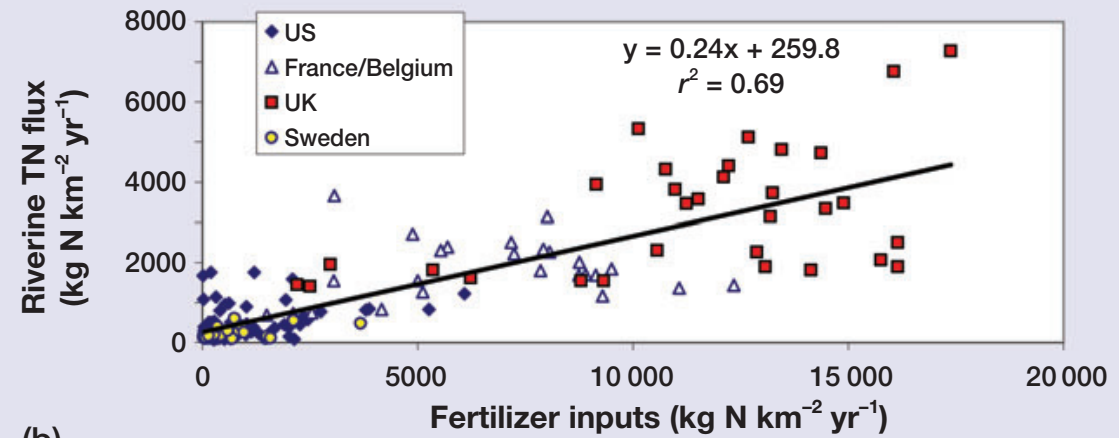

(b)

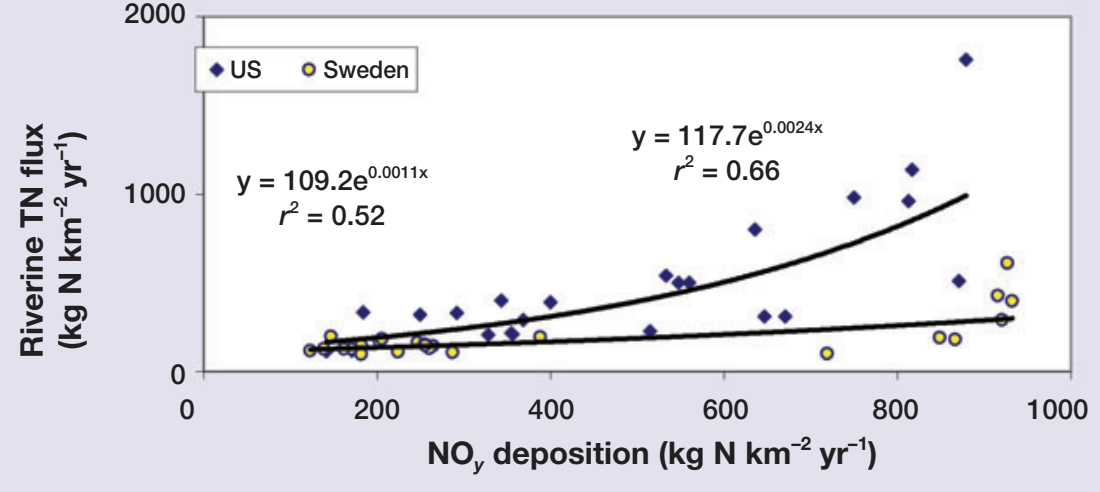

Figure 3. (a) Synthetic N fertilizer is often the major term of NANI in watersheds, and fertilizer alone is significantly correlated with the average flux of $N$ in rivers across the 154 watersheds $\left(\mathrm{P}=5 \times 10^{-41}\right)$. (b) The atmospheric deposition of oxidized $N\left(N_{y}\right)$ is an important term of NANI in some watersheds; for those watersheds where this deposition equals or exceeds the input of synthetic $N$ fertilizer, deposition is significantly correlated with riverine $N$ fluxes $\left(\mathrm{P}=2 \times 10^{-16}\right.$ for the US watersheds and $\mathrm{P}=7 \times 10^{-5}$ for the Swedish watersheds). Note that the $\mathrm{N}$ in $\mathrm{NO}_{y}$ deposition originates largely from the combustion of fossil fuels, and also contributes to acid rain.

various locations, the scale is even coarser. We searched for a size-threshold effect on the utility of the NANI approach by analyzing the goodness of fit between NANI and riverine $\mathrm{N}$ flow while stepwise deleting one watershed at a time from the analysis by dropping the smallest remaining watershed at each step (WebFigure 1). The goodness of fit in the relationship gradually improved as watersheds were deleted, but in general we saw few if any sharp break points. This suggests that the NANI approach is reasonably robust and predictive, even in watersheds that are far smaller than those to which the approach has usually been applied in the past. For many of the analyses in this paper, we concentrate on watersheds greater than $250 \mathrm{~km}^{2}$. These analyses often show similar statistical results when cutoffs of $250 \mathrm{~km}^{2}, 500 \mathrm{~km}^{2}$, or $1000 \mathrm{~km}^{2}$ are used, but far less statistically powerful results when watersheds smaller than $250 \mathrm{~km}^{2}$ are included.

We also explored incorporating TNI by adding the natural rate of N fixation to NANI. The TNI approach is conceptually attractive, because the mass balance for $\mathrm{N}$ input terms is more complete (Boyer et al. 2002). However, $\mathrm{N}$ fixation is difficult to measure, and data for particular regions or watersheds are seldom available.
Even when such data are available, they are difficult to extrapolate to the watershed scale. We estimated the natural rate of $\mathrm{N}$ fixation from the regression between evapotranspiration and fixation developed by Cleveland et al. (1999) for a global dataset on $\mathrm{N}$ fixation. Evapotranspiration for our watersheds was estimated as the difference between precipitation and freshwater discharge. Riverine $\mathrm{N}$ fluxes from the watersheds are significantly correlated with both TNI and NANI (WebFigure 2). The two relationships are extremely similar, and a test of coincidence of the regressions shows no significant differences between the two. Given that the TNI approach requires the estimation of a highly uncertain term (ie the natural rate of $\mathrm{N}$ fixation) and does not significantly improve the correlation with riverine $\mathrm{N}$ flux, we prefer the NANI approach.

\section{The influence of the individual NANI terms}

Each NANI component contributes to riverine $\mathrm{N}$ flux. For many of the watersheds included here, synthetic $\mathrm{N}$ fertilizer is the single largest input. Not surprisingly, therefore, fertilizer input alone is significantly correlated with riverine $\mathrm{N}$ flux (Figure 3a). More surprising is the finding that agricultural $\mathrm{N}$ fixation alone (WebFigure 3) and $\mathrm{NO}_{y}$ deposition alone (WebFigure 4) are also correlated with riverine $\mathrm{N}$ flux. The contribution of atmospheric deposition holds for the entire dataset but becomes quite notable when looking at the subset of watersheds for which $\mathrm{NO}_{y}$ deposition is greater than fertilizer inputs (Figure $3 \mathrm{~b}$ ). This group only includes watersheds in the US and in Sweden; we have fit separate regressions for the watersheds in the two countries. Both show an exponential response with proportionately greater $\mathrm{N}$ flux in rivers as deposition increases above $500-900 \mathrm{~kg} \mathrm{~N} \mathrm{~km}^{-2} \mathrm{yr}^{-1}$. This is consistent with the threshold for downstream leakage of $\mathrm{N}$ from forests receiving atmospheric deposition as described in Aber et al. (2003). However, unlike the forests studied by Aber et al. (2003), the watersheds in our analysis receive other NANI components. The higher riverine $\mathrm{N}$ flux for a given input of $\mathrm{N}$ deposition in the US as compared with that in Sweden is probably the result of these other NANI components being greater in the US watersheds (WebTable 1).

The net input of $\mathrm{N}$ in food and animal feeds has two 
relationships with river $\mathrm{N}$ flux. This net input is positively correlated with riverine $\mathrm{N}$ flux when the net food and feed term is positive, and is negatively correlated with riverine $\mathrm{N}$ flux when the net food and feed term is negative (Figure 4). The positive correlation for positive net inputs in food and feed is driven by sewage and animal wastes from the imported food and feeds. The watersheds that have large net negative inputs of $\mathrm{N}$ in food and feeds (ie positive net exports) are agricultural regions that export crop products. In these, the export of food and feed is supported by large inputs of synthetic $\mathrm{N}$ fertilizer and/or $\mathrm{N}$ fixation. Indeed, over the entire dataset of 154 watersheds, the net food/feed term is negatively correlated with the sum of fertilizer and agricultural $\mathrm{N}$ fixation (WebFigure 5). Thus, the negative correlation of the net food/feed term with riverine $\mathrm{N}$ flux is clearly driven by fertilizer use and $\mathrm{N}$ fixation.

\section{The role of climate}

In an earlier paper that looked at only 16 northeastern US watersheds, the fraction of NANI exported in rivers was clearly correlated with precipitation and discharge but not with temperature (Howarth et al. 2006). For a similar analysis that included both northeastern and southeastern US watersheds, Schaefer and Alber (2007) found that the fraction of NANI exported was correlated with all of these climate variables, but suggested that temperature had the strongest relationship. Conversely, Schaefer et al. (2009) found no relationship between the fraction of NANI exported and any climate variable in the western US.

The riverine $\mathrm{N}$ flux data in this paper and in Howarth et al. (2006), Schaefer and Alber (2007), and Schaefer et al. (2009) are all averages for multiple years. Other studies have demonstrated that when examining year-by-year patterns, the fraction of NANI exported is greater in years with high discharge and less in years with low discharge, but this can be explained as storage of $\mathrm{N}$ in the landscape in dry years followed by flushing in wet years (McIsaac et al. 2001; Donner and Scavia 2007; Han et al. 2009; David et al. 2010). For watersheds with low inputs of anthropogenic $\mathrm{N}$, long-term average riverine $\mathrm{N}$ fluxes are greater in those having higher discharge, but this may be the result of differences in rates of natural $\mathrm{N}$ fixation (Lewis et al. 1999; Lewis 2002; Howarth et al. 2006).

Here, we return to the question raised in Howarth et al. (2006): is there an influence of climate on the long-term average riverine $\mathrm{N}$ flux that is related to the long-term sinks in the landscape, which are primarily denitrification and accumulation of $\mathrm{N}$ in soils and biomass (van Breemen et al. 2002)? That is, with the larger dataset now available, is there an influence of climate on the average amount of NANI exported over multiple-year periods aside from interannual storage and flushing? The answer is yes: the fraction of NANI exported in long-term average riverine $\mathrm{N}$ flux is significantly correlated with temperature, precipitation, and discharge (WebFigure 6). The explanatory power of the relationships is weak for both temperature and precipitation $\left(r^{2}=0.03\right.$ and 0.11 ; $P=0.037$ and $9 \times 10^{-5}$, respectively). However, discharge is highly correlated with the fraction of NANI exported in rivers $\left(r^{2}=0.41, P=5 \times 10^{-16}\right.$; WebFigure 6).

One might question whether the relationship between the fraction of NANI exported and discharge is a result of auto-correlation, because discharge information is used to estimate riverine $\mathrm{N}$ flux. The same question can be raised about studies that demonstrate an influence of discharge on long-term average $\mathrm{N}$ flux from watersheds with low human impact (Lewis et al. 1999; Lewis 2002) or that show the relationship of interannual $\mathrm{N}$ flux to discharge (McIsaac et al. 1999; Donner and Scavia 2007; Han et al. 2009; David et al. 2010). In fact, this is not of concern, because the discharge information used to estimate riverine $\mathrm{N}$ fluxes is taken at short time intervals and multiplied by the $\mathrm{N}$ concentration over the same time interval. The $\mathrm{N}$ concentration generally is not a simple function of this short time discharge, and concentrations can be higher or lower at different discharge rates, with different 
trends in different systems (McDiffett et al. 1989; Bachman et al. 2002). Although annual average discharge itself is indeed correlated with riverine $\mathrm{N}$ flux across the watersheds in this study $(P=0.007$ for the slope; WebFigure 7), the relationship has rather little explanatory power $\left(r^{2}=0.056\right)$. In part this is because of the human domination of the $\mathrm{N}$ cycle, which is captured in NANI. Discharge better explains the fraction of NANI exported (WebFigure 6) than riverine N flux (WebFigure 7).

We used a multiple regression approach to explore the influence of climate on $\mathrm{N}$ fluxes in rivers, excluding small watersheds $\left(<250 \mathrm{~km}^{2}\right.$; WebTable 2$)$. We tested models to estimate the riverine $\mathrm{N}$ flux based on various functions of NANI, discharge, and temperature, as well as models that either did or did not force the intercept through zero. We followed the guidance of Hirsch et al. (1993) and only tested simple regression models based on physically plausible explanations for relating the climate variable to riverine $\mathrm{N}$ flow. The intercept term was never significant in these models, and here we show only the models with the zero intercept. Temperature alone as a term was never significant (WebTable 2). On the other hand, NANI terms were always significant, as were NANI-discharge interaction terms. The most parsimonious of these models is based on a NANI term and a separate NANIdischarge interaction term, with both being highly significant: predicted flux $=$ NANI $(0.00035 Q+0.115)$, where $Q$ is the average discharge. The predicted riverine $\mathrm{N}$ export is highly correlated $\left(r^{2}=0.86, P=1 \times\right.$ $10^{-10}$ ) with the measured riverine $\mathrm{N}$ flux and is centered on the 1:1 line (WebFigure 8). For our large set of watersheds in Europe and the US, the multi-year average flux of $\mathrm{N}$ in rivers can be explained with a great deal of precision based simply on this NANI-discharge model.

\section{Conclusions}

The NANI approach provides a simple and robust method for estimating the flux of $\mathrm{N}$ from temperatezone watersheds, including relatively small watersheds, as well as insight on the major sources of $\mathrm{N}$ pollution in the landscape. This evaluation of sources can provide guidance to water-quality managers regarding where to focus their efforts. For instance, field-scale agricultural practices should be the main focus for watersheds where $\mathrm{N}$ fertilizer dominates NANI, but treatment of wastes should be the greater focus for watersheds where the net import of $\mathrm{N}$ in food and feeds dominates. Although NANI alone is quite predictive for estimating riverine $\mathrm{N}$ flux, a model that includes both NANI and discharge increases the precision of the estimate. That the average flux of $\mathrm{N}$ in rivers increases as average multi-year discharge increases has profound implications for managing $\mathrm{N}$ pollution. Our finding suggests fewer long-term sinks for $\mathrm{N}$ in the landscape as it becomes wetter, with a greater percentage of NANI exported to coastal waters. Managers must consider this influence on $\mathrm{N}$ pollution in the face of a changing climate, where in the future some regions will become wetter and others drier.

\section{Acknowledgements}

Funding was supplied in part from the National Oceanic and Atmospheric Administration (NOAA) through the Coastal Hypoxia Research Program, the US Department of Agriculture through the Agriculture, Energy, and Environment Program at Cornell University, and David R Atkinson through an endowment given to Cornell to support a professorship awarded to RH. This paper resulted from workshops held in Sigtuna, Sweden, and Paris, France, funded by Baltic Nest and Nine-ESF. This is Contribution \#CHRP 138 from the NOAA Coastal Hypoxia Research Program.

\section{References}

Aber J, Goodale C, Ollinger SV, et al. 2003. Is N deposition altering the $\mathrm{N}$ status of northeastern forests? BioScience 53 : 375-89.

Alexander RB, Johnes PJ, Boyer EW, and Smith RA. 2002. A comparison of models for estimating the riverine export of $\mathrm{N}$ from large watersheds. Biogeochemistry 57/58: 295-339.

Bachman LJ, Krantz DE, and Bohlke J. 2002. Hydrogeologic framework, ground-water geochemistry, and assessment of $\mathrm{N}$ yield from base flow in two agricultural watersheds, Kent County, Maryland. Cincinnati, OH: US Environmental Protection Agency. EPA/600/R-02/008.

Billen G, Garnier J, Nemery J, et al. 2007. A long term view of nutrient transfers through the Seine River continuum. Sci Total Environ 275: 80-97.

Billen G, Thieu V, Garnier J, and Silvestre M. 2009. Modelling the $\mathrm{N}$ cascade in regional watersheds: the case study of the Seine, Somme and Scheldt rivers. Agr Ecosyst Environ 133: 234-46.

Boyer EW, Goodale CL, Jaworski NA, and Howarth RW. 2002. Anthropogenic $\mathrm{N}$ sources and relationships to riverine $\mathrm{N}$ export in the northeastern USA. Biogeochemistry 57/58: 137-69.

Boyer EW, Howarth RW, Galloway J, et al. 2006. Riverine N export from the continents to the coasts. Global Biogeochem Cy 20: GB1S91; doi:10.1029/2005GB002537.

Cleveland CC, Townsend AR, Schimel DS, et al. 1999. Global patterns of terrestrial biological $\mathrm{N}\left(\mathrm{N}_{2}\right)$ fixation in natural systems. Global Biogeochem Cy 13: 623-45.

David MB, Drinkwater LE, and McIsaac GF. 2010. Sources of nitrate yields in the Mississippi River basin. J Environ Qual 39: $1657-67$.

Donner SD and Scavia D. 2007. How climate controls the flux of $\mathrm{N}$ by the Mississippi River and the development of hypoxia in the Gulf of Mexico. Limnol Oceanogr 52: 856-61.

EPA-SAB (US Environmental Protection Agency-Science Advisory Board). 2008. Hypoxia in the northern Gulf of Mexico: an update by the EPA Science Advisory Board. Washington, DC: US EPA. Report EPA-SAB-08-003.

Galloway JN, Dentener FJ, Capone DG, et al. 2004. N cycles: past, present, and future. Biogeochemistry 70: 153-226. 
Han $\mathrm{H}$ and Allan JD. 2008. Estimation of $\mathrm{N}$ inputs to catchments: comparison of methods and consequences for riverine export prediction. Biogeochemistry 91: 177-99.

Han H, Allan JD, and Scavia D. 2009. Influence of climate and human activities on the relationship between watershed $\mathrm{N}$ input and river export. Environ Sci Technol 43: 1916-22.

Hirsch RM, Helsel DR, Cohn TA, and Gilroy EJ. 1993. Statistical analysis of hydrologic data. In: Maidment DR (Ed). Handbook of hydrology. New York, NY: McGraw-Hill.

Hong B, Swaney DP, and Howarth RW. 2011. A toolbox for calculating net anthropogenic nitrogen inputs (NANI). Environ Modell Softw 26: 623-33.

Howarth RW, Billen G, Swaney D, et al. 1996. Riverine inputs of $\mathrm{N}$ to the North Atlantic Ocean: fluxes and human influences. Biogeochemistry 35: 75-139.

Howarth RW, Ramakrishna K, Choi E, et al. 2005. Nutrient management, responses assessment. In: Ecosystems and human well-being, vol 3. Washington, DC: Island Press.

Howarth RW, Swaney DP, Boyer EW, et al. 2006. The influence of climate on average $\mathrm{N}$ export from large watersheds in the northeastern United States. Biogeochemistry 79: 163-86.

Howarth RW, Chan F, Conley D, et al. 2011. Coupled biogeochemical cycles: eutrophication and hypoxia in coastal marine ecosystems. Front Ecol Environ 9: 18-26.

Lewis WM. 2002. Yield of N from minimally disturbed water- sheds of the United States. Biogeochemistry 57/58: 375-85.

Lewis WM, Melack JM, McDowell WH, et al. 1999. N yields from undisturbed watersheds in the Americas. Biogeochemistry 46: 149-62.

McDiffett WF, Beidler AW, Dominick TF, and McCrea KD. 1989. Nutrient concentration-stream discharge relationships during storm events in first-order streams. Hydrobiologia 179: 97-102.

McIsaac GF, David MF, Gertner GZ, and Goolsby DA. 2001. Net anthropogenic $\mathrm{N}$ input to the Mississippi River basin and nitrate flux to the Gulf of Mexico. Nature 414: 166-67.

NRC (National Research Council). 2000. Clean coastal waters: understanding and reducing the effects of nutrient pollution. Washington, DC: National Academies Press.

Peierls BL, Caraco NF, Pace ML, and Cole JJ. 1991. Human influence on river N. Nature 350: 386-87.

Schaefer SC and Alber MA. 2007. Temperature controls a latitudinal gradient in the proportion of watershed $\mathrm{N}$ exported to coastal ecosystems. Biogeochemistry 85: 333-46.

Schaefer SC, Hollibaugh JT, and Alber M. 2009. Watershed N input and riverine export on the west coast of the US. Biogeochemistry 93: 219-33.

van Breemen N, Boyer EW, Goodale CL, et al. 2002. Where did all the $\mathrm{N}$ go? Fate of $\mathrm{N}$ inputs to large watersheds in the northeastern USA. Biogeochemistry 57/58: 267-93.

\section{Excess Nitrogen in the U.S. Environment: Trends, Risks, and Solutions}

Nitrogen is both an essential nutrient and a pollutant, a benefit and a hazard, depending on form, location, and quantity. Agriculture, industry, and transportation have spread nitrogen liberally around the planet, with complex and interrelated consequences for ecological communities and human health. This Issue tracks nitrogen through its different chemical forms and biological incarnations as it progresses across economic, environmental, and regulatory bounds. The authors argue for a systematic approach to managing nitrogen and its consequences.

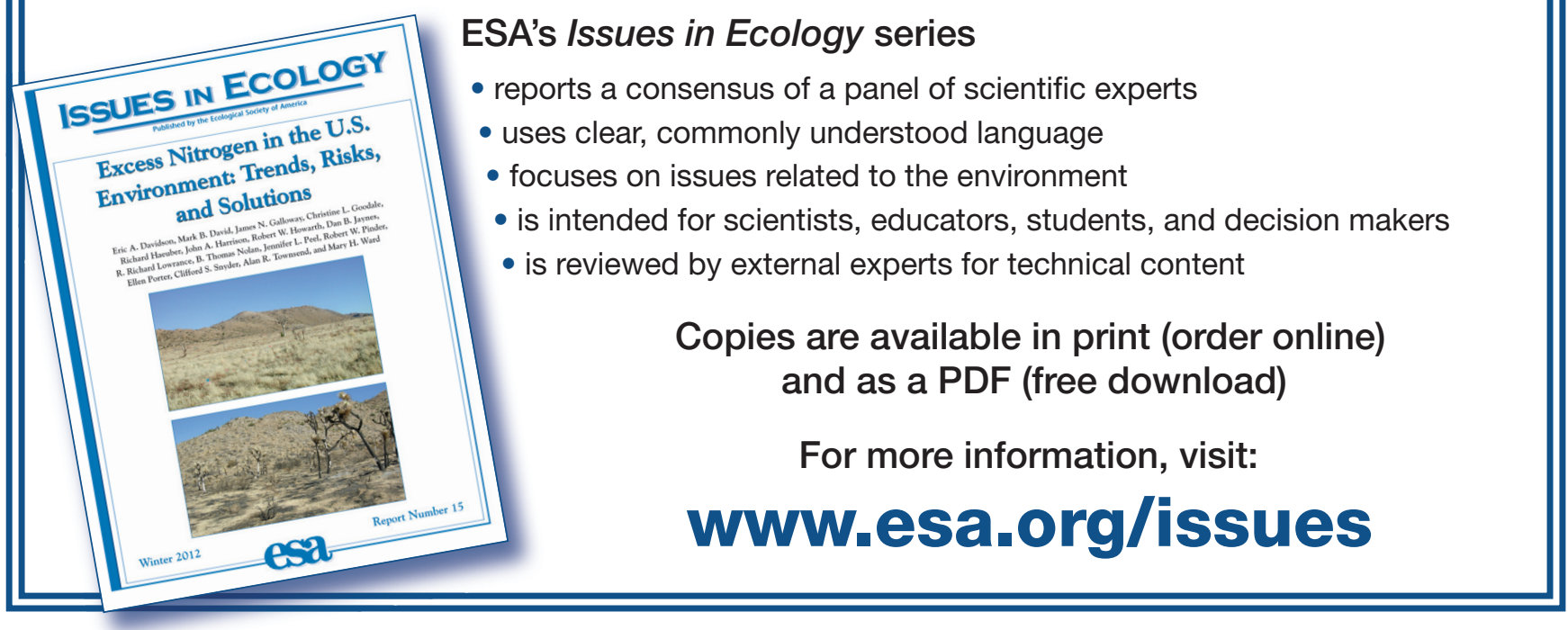

